\title{
Laparoscopic Choledochal Cyst Excision and Hepaticojejunostomy: A Case Series
}

\author{
Eun-jung Koo, M.D., Eunyoung Jung, M.D., Soon-Ok Choi, M.D., Ph.D. \\ Department of Pediatric Surgery, Keimyung University Dongsan Medical Center, Daegu, Korea
}

Purpose: Choledochal cysts are congenital dilatations of the biliary tract and are generally surgically excised. Laparoscopic total excision of choledochal cysts and hepaticojejunal biliary tract reconstruction has gained acceptance among pediatric surgeons. We report our early experience with this procedure.

Methods: From May 2013 to April 2016, 10 consecutive patients (7 females and 3 males) underwent laparoscopic choledochal cyst excision and hepaticojejunostomy at our center. We retrospectively reviewed their medical records for age, sex, clinical symptoms, Todani classification, anomalous pancreaticobiliary duct union, operative time, starting day for enteral feeding, complications, and hospital stay.

Results: The median patient age was 22 months. Four patients were aged less than 6months, 3 of whom received prenatal diagnosis using ultrasonography. Patients presented with abdominal pain, jaundice, vomiting and fever. No abdominal mass was palpated in any patient. One patient was classified as Todani type Ia, 4 as Ic, and 5as IVa. Six patients had an anomalous pancreaticobiliary duct union. The mean operative time was 319.4 minutes. There were no surgery-related complications. Sips of water were allowed from mean postoperative day 2.4 and regular diet from mean postoperative day 3.4. The mean hospital stay was 6.5 days.

Conclusion: Laparoscopic excision of choledochal cyst and hepaticojejunostomy in children is feasible with favorable cosmesis.

Keywords: Choledochal cyst, Laparoscopy, Child

This is an Open Access article distributed under the terms of the Creative Commons Attribution Non-Commercial License (http:// creativecommons.org/licenses/by-nc/4.0/) which permits unrestricted non-commercial use, distribution, and reproduction in any medium, provided the original work is properly cited.

\author{
Received December 12, 2016 \\ Revised 1st January 31, 2017 \\ 2nd March 6, 2017 \\ Accepted March 8, 2017 \\ Corresponding author \\ Eunyoung Jung \\ Department of Pediatric Surgery, \\ Keimyung University Dongsan \\ Medical Center, 56 Dalseong-ro, \\ Jung-gu, Daegu 41931, Korea \\ Tel: +82-53-250-8091 \\ Fax: +82-53-250-7322 \\ E-mail: eyjung@dsmc.or.kr
}

\section{INTRODUCTION}

Choledochal cysts are congenital dilatations of the biliary tract; they are more prevalent among Asian females and are commonly associated with anomalous pancreaticobiliary duct union (APBDU). ${ }^{1,2}$ Choledochal cyst related complications include cholecystitis, cholangitis, pancreatitis, cholelithiasis, and perforation of the choledochal cyst. Furthermore, choledochal cysts can transform into biliary malignancies if not treated.,
Hence, complete surgical excision of the choledochal cyst and enterobiliary reconstruction has been recommended as the standard treatment.

Since its first report in $1995,{ }^{4}$ laparoscopic choledochal cyst excision has gained acceptance as a safe and effective approach among pediatric surgeons. ${ }^{5-7}$ Our center started performing laparoscopic choledochal cyst excision and hepaticojejunostomy in May 2013. Herein we report our early experience with this procedure. 


\section{MATERIALS AND METHODS}

From May 2013 to April 2016, 10 consecutive patients underwent laparoscopic choledochal cyst excision and hepaticojejunostomy at our center. We retrospectively reviewed the medical records of these patients. The variables investigated were age, sex, clinical symptoms, Todani classification, anomalous pancreaticobiliary duct union, operative time, starting day for enteral feeding, complications, and hospital stay. All procedures were performed by the same pediatric surgery team. This study was approved by the ethics committee/institutional review board (IRB no. 2016-11-072) of our medical center.

\section{Operative techniques}

The patient was placed in the supine position under general anesthesia. The patient's hip was positioned at the end of the table, with the legs on extended supports. Infants and small children were placed in the frog-leg position, whereas larger children were placed in the dorsal lithotomy position, with the legs in stirrups. The operating surgeon stood between the patient's legs and the assistant stood on the surgeon's right side (Fig. 1). A nasogastric tube was inserted to decompress the stomach, and a Foley catheter was inserted. We used a fourport technique. A $10-\mathrm{mm}$ (or $5 \mathrm{~mm}$ for infants) umbilical trocar was inserted for the camera and a pneumoperitoneum was created using $\mathrm{CO}_{2}$ gas at a pressure of $10 \sim 12 \mathrm{mmHg}$. Three additional trocars $(3 \sim 5 \mathrm{~mm})$ were inserted in the right and left lower quadrants. The right flank port was used to hold the gallbladder to aid in dissection and anastomosis of the bile duct. This trocar was also used to insert a closed drain at the site of hepaticojejunostomy. The $3 \mathrm{~mm} / 5 \mathrm{~mm}$ working port and the assistant port were placed on the left upper abdomen under laparoscopic guidance. Intraoperative cholangiography was performed for all 10 patients (Fig. 2A). The cystic artery and duct were dissected and ligated with intracorporeal $\mathrm{su}^{-}$ tures or with $5-\mathrm{mm} \mathrm{Hem}^{-} \mathrm{O}^{- \text {Lok }^{\circledR}}$ clips (Teleflex Inc., Morris-

A

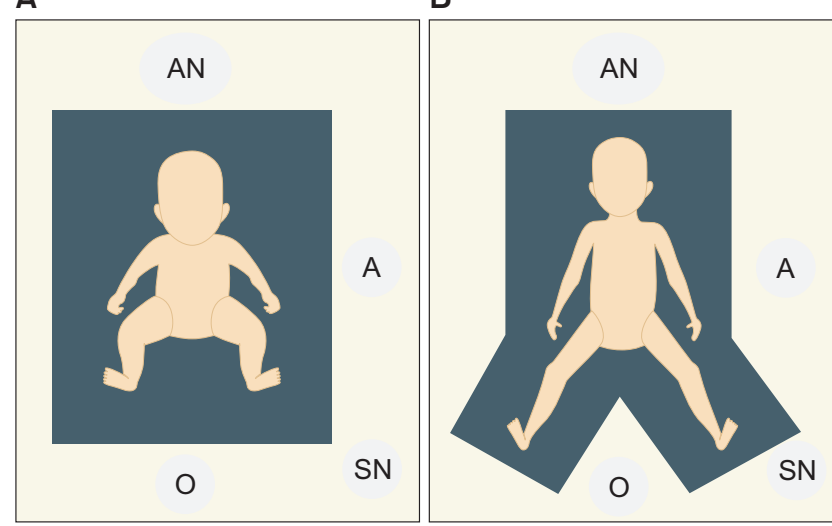

Fig. 1. Positions for the operator, assistant, scrub nurse, and anesthesiologist. (A) Position for infants. (B) Position for children. 0 = operator; $A=$ assistant; $S N=$ scrub nurse; $A N=$ anesthesiologist.
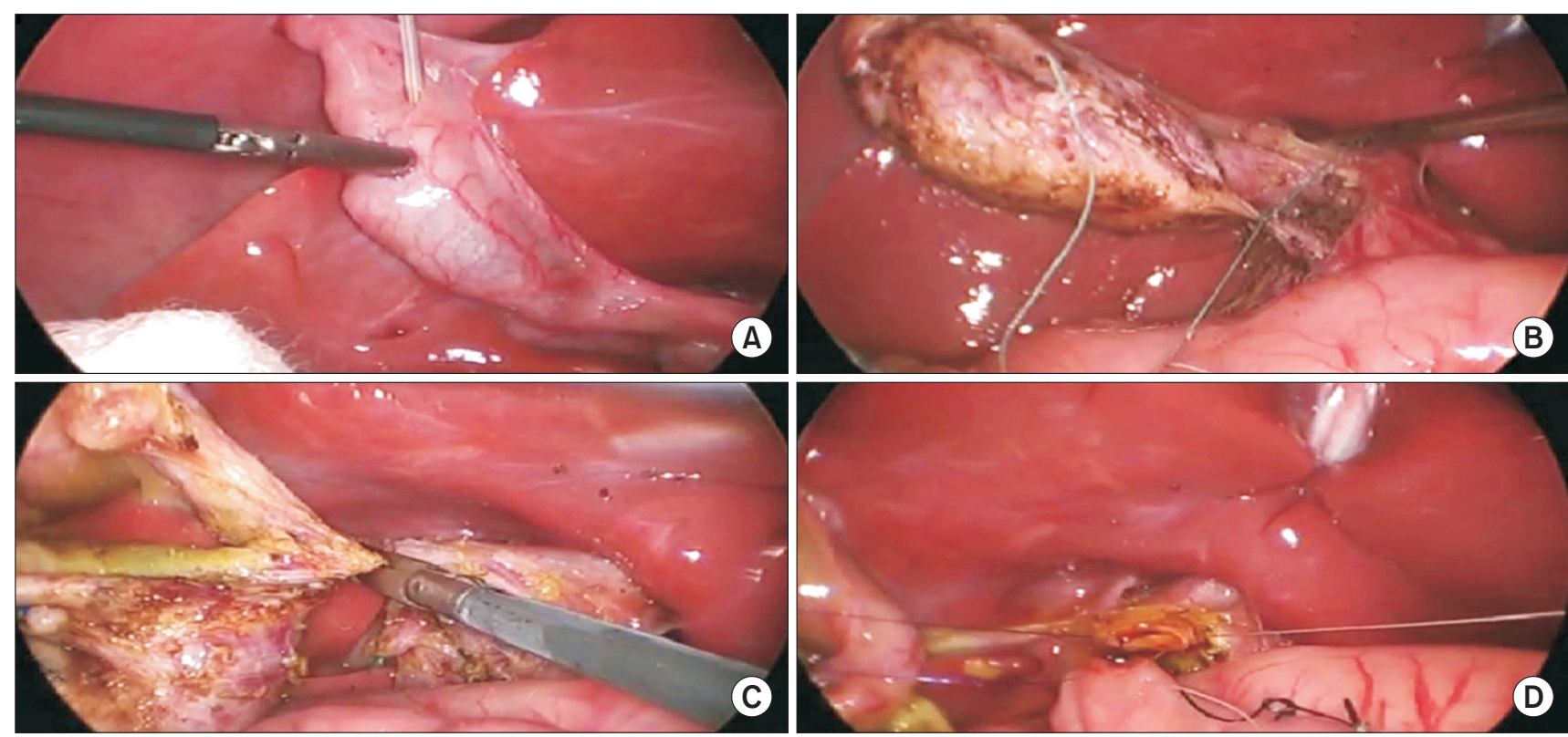

Fig. 2. The laparoscopic operating field. (A) Intraoperative cholangiography. (B) Ligation of distal CBD. (C) Resection of proximal CBD. (D) Hepaticojejunostomy. 
ville, NC, USA). The common bile duct (CBD) was dissected using monopolar hook electrocautery. The distal CBD was ligated using 4-0 Ethibond suture (ETHICON Inc., Somerville, NJ, USA) and 5-mm Hem-o-Lok clips, and then separated (Fig. 2B). Subsequently, the proximal CBD was dissected to the normal $\mathrm{CBD}$ diameter level. A one-point suture with black silk was performed on the jejunum $20 \mathrm{~cm}$ distal from the ligament of Treitz to identify the resection line of jejunum. The umbilical incision was extended superiorly to $1 \mathrm{~cm}$ and the small bowel was extracted through the umbilical incision. The jejunum was resected at approximately $20 \mathrm{~cm}$ from the ligament of Treitz using the GIA ${ }^{\circledR}$ stapler (MedtronicInc., Minneapolis, MN, USA), and a Roux-en-Y jejunojejunostomy was created with an extracorporeal end-to-side anastomosis. The mean length of the Roux loop was $50 \mathrm{~cm}$ (range, 40 60 $\mathrm{cm})$. The small bowel was reintroduced into the abdominal cavity. The dissected proximal CBD was excised at the level of the normal CBD (Fig. 2C). Retrocolic hepaticojejunostomy was performed intracorporeally with Monosyn (B. Braun, Melsungen, Germany) 5-0 interrupted sutures: stitches for the posterior wall preferably and then another for the anterior wall subsequently. The anastomosis was constructed a few millimeters from the stapled end of the Roux limb to prevent a blind pouch (Fig. 2D).

\section{RESULTS}

Seven patients were females and 3 were males. The median age at the time of surgery was 22 months (range, 2 90 months). Four of the 10 patients were aged less than 6 months; diagnosis was made using prenatal ultrasonography in 3 of these patients, while it was incidental (during ultrasonography on the second day of birth) in 1. The mean age for these patients was 3.75 months (range, 2 5 months). Overall, one patient was classified as Todani type Ia, 4 as Ic, and 5 as IVa. Six patients had APBDU (Table 1).

Preoperative symptoms and signs were assessed (Table 2). No patients had palpable abdominal masses. Chief complaints included abdominal pain $(n=4)$, jaundice $(n=3)$, vomiting $(n=4)$, and fever $(n=2)$. Four of 10 patients had pancreatitis and 1 had cholangitis. Three patients had stones in the CBD.

The mean operative time was 319.4 minutes (range, 255 465 minutes) (Fig. 3), including the time for intraoperative cholangiography. For the 4 patients aged less than 6 months, the mean operative time was 284.5 minutes (range, 255 318 minutes). There were no surgery-related major complications such as anastomosis leakage, stricture, cholangitis, bleeding, and ileus. Two patients developed fever ( 1 on postoperative day 5 and the other on postoperative day 8). One patient had upper respiratory tract infection and was treated with intravenous
Table 1. Characteristics of patients $(N=10)$

\begin{tabular}{|cc|}
\hline \multicolumn{1}{|c}{ Characteristic } & Value $(\mathbf{n})$ \\
\hline Sex & \\
Male & 3 \\
Female & 7 \\
\hline Age at surgery (median, months) & 22 (range, $2 \sim 90)$ \\
\hline Todani classification (MRCP) & \\
la & 1 \\
IC & 4 \\
IV & 5 \\
APBDU & 6 \\
\hline
\end{tabular}

APBDU $=$ anomalous pancreaticobiliary duct union; $\mathrm{MRCP}=$ magnetic resonance cholangiopancreatography.

Table 2. Preoperative symptoms and signs

\begin{tabular}{|ll|}
\hline Symptom/sign & $\mathrm{n}(\%)$ \\
\hline Pain & $4(40)$ \\
\hline Jaundice & $3(30)$ \\
\hline Palpable RUQ mass & $0(0)$ \\
\hline Vomiting & $4(4)$ \\
\hline Fever & $2(2)$ \\
\hline Cholangitis & $1(1)$ \\
\hline Pancreatitis & $4(40)$ \\
\hline CBD stones & $3(30)$ \\
\hline Incidental diagnosis & $1(10)$ \\
\hline Antenatal detection & $3(30)$ \\
\hline
\end{tabular}

$\mathrm{CBD}=$ common bile duct; $\mathrm{RUQ}=$ right upper quadrant.

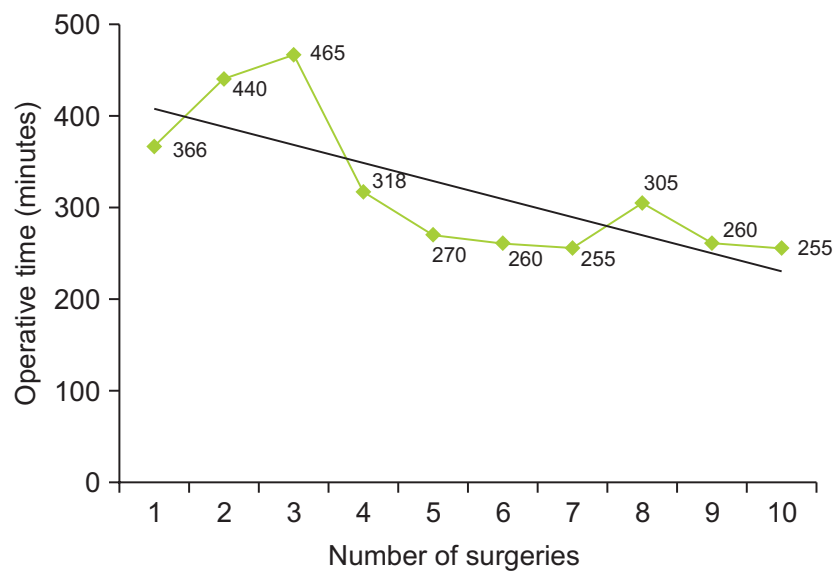

Fig. 3. Operative time (minutes). 
Table 3. Operative and postoperative outcomes

\begin{tabular}{lc}
\hline \multicolumn{1}{c}{ Outcome } & Mean (range) \\
\hline Operative time (minutes) & $319.4(255 \sim 465)$ \\
\hline Sips of water (postoperative day) & $2.4(1 \sim 3)$ \\
\hline Regular diet (postoperative day) & $3.4(2 \sim 4)$ \\
\hline Postoperative hospital stay (days) & $6.5(5 \sim 9)$ \\
Immediate postoperative complications & \\
Major complications (anastomosis leakage, stricture, cholangitis, bleeding, ileus) & 0 \\
Fever & 2 \\
Wound complications & 0 \\
\hline
\end{tabular}

antibiotics for 3 days. Another patient had dehydration but recovered with fluid resuscitation. No wound-related complications were reported. The cosmetic outcome was excellent (Fig. 2). Sips of water were allowed from mean postoperative day 2.4 (range, 1-3 days), and diet including milk feeding was started on mean postoperative day 3.4 (range, $2 \sim 4$ days). The mean hospital stay was 6.5 days (range, $5 \sim 9$ days) (Table 3).

\section{DISCUSSION}

Laparoscopic choledochal cyst excision and hepaticojejunostomy in children is widely accepted, and several studies have described the advantages of laparoscopic surgery, ${ }^{2,6}$ Liem et al. and Nguyen Thanh et al. reported laparoscopic choledochal cyst excision and reconstruction of the biliary-digestive system as safe and effective with cases of a large number of choledochal cyst patients. ${ }^{2,8}$

Diao at al. ${ }^{9}$ reported a learning curve for laparoscopic hepaticojejunostomy in children with choledochal cysts; no differences in operative time were observed between the open surgery and the laparoscopic surgery groups. In our study, a long operative time was required initially, it shortened with improving surgeon's proficiency (Fig. 3). It remains unclear whether the learning curve was overcome based on experience only with cases of choledochal cysts, because of the very low incidence of this disease entity. It is possible that the improvement in surgical skill, and hence the operative time, was a result of the surgeons gaining experience with other common laparoscopic pediatric surgeries such as laparoscopic appendectomy and laparoscopic hernioplasty.

Laparoscopic surgery is associated with technical challenges, particularly in pediatric cases. The abdominal cavity in pediatric patients is very small compared to that in adults; the space constraints make free use of laparoscopic instruments difficult. Nevertheless, the surgeon should ensure precise laparoscopic suturing for a successful hepaticojejunostomy. $\mathrm{He}^{-}$ paticojejunostomy is difficult even with open surgery owing to the narrow space and the small diameter of the proximal CBD in pediatrics. The laparoscopic view might help overcome the challenges of space constraints in open surgery if the surgeon is proficient in laparoscopic suturing.

In our early experience, the outcome has been favorable, with no conversion to open surgery even in complicated cases. One patient had cholangitis and 4 had pancreatitis. Three patients had CBD stones. They underwent preoperative endoscopic retrograde cholangiopancreatography and endoscopic sphincterotomy. Kim et al. suggested broadening the indications for the laparoscopic approach to cholangitis- and/ or pancreatitis-associated cases, with adequate preoperative management.

In our study, diagnosis was prenatal in 3 cases, and in 1 case, it was incidental (during ultrasonography on the $2^{\text {nd }}$ day of birth). They recovered satisfactorily without complications. Chan et al. ${ }^{10}$ reported on the laparoscopic management of 10 cases with antenatally detected choledochal cysts and the safety of laparoscopic excision and hepaticojejunostomy. Further studies on patients with antenatal diagnosis might be needed to determine the best timing for surgery and the longterm outcomes.

All patients in our study recovered without major surgeryrelated complications. Biliary tract obstruction may occur after laparoscopic hepaticojejunostomy. ${ }^{11}$ Ono et al. ${ }^{3}$ reported liver dysfunction, dilatation of intrahepatic bile ducts, recurrent abdominal pain, and biliary tract malignancy as longterm complications after choledochal cyst excision and hepaticojejunostomy. The laparoscopic approach can magnify the operative view, which may assist in dissecting the whole choledochal cyst without a remnant duct, and in anastomosis. $\mathrm{Fu}^{-}$ ture long-term studies are required to compare the incidence of malignancy between open and laparoscopic surgeries.

In conclusion, our results suggest that laparoscopic excision of choledochal cysts and hepaticojejunostomy in children is a 
safe and feasible method, with an excellent cosmetic outcome.

\section{REFERENCES}

1) Miyano T, Yamataka A, Li L. Congenital biliary dilatation. Semin Pediatr Surg 2000;9(4):187-195.

2) Liem NT, Pham HD, Dung le A, Son TN, Vu HM. Early and intermediate outcomes of laparoscopic surgery for choledochal cysts with 400 patients. J Laparoendosc Adv Surg Tech A 2012;22(6): 599-603.

3) Ono S, Fumino S, Shimadera S, Iwai N. Long-term outcomes after hepaticojejunostomy for choledochal cyst: a 10- to 27-year follow-up. J Pediatr Surg 2010;45(2):376-378.

4) Farello GA, Cerofolini A, Rebonato M, Bergamaschi G, Ferrari C, Chiappetta A. Congenital choledochal cyst: video-guided laparoscopic treatment. Surg Laparosc Endosc 1995;5(5):354-358.

5) Zhen $C$, Xia Z, Long L, et al. Laparoscopic excision versus open excision for the treatment of choledochal cysts: a systematic review and meta-analysis. Int Surg 2015;100(1):115-122.
6) Qiao G, Li L, Li S, et al. Laparoscopic cyst excision and Roux-Y hepaticojejunostomy for children with choledochal cysts in China: a multicenter study. Surg Endosc 2015;29(1):140-144.

7) Lee JH, Kim SH, Kim HY, Choi YH, Jung SE, Park KW. Early experience of laparoscopic choledochal cyst excision in children. J Korean Surg Soc 2013;85(5):225-229.

8) Nguyen Thanh L, Hien PD, Dung le A, Son TN. Laparoscopic repair for choledochal cyst: lessons learned from 190 cases. J Pediatr Surg 2010;45(3):540-544.

9) Diao M, Li L, Cheng W. Laparoscopic versus open Roux-en-Y hepatojejunostomy for children with choledochal cysts: intermediate-term follow-up results. Surg Endosc 2011;25(5):1567-1573.

10) Chan KW, Lee KH, Tsui SY, Mou JW, Tam YH. Laparoscopic management of antenatally detected choledochal cyst: a 10-year review. Surg Endosc 2016;30(12):5494-5499.

11) Diao M, Li L, Cheng W. Recurrence of biliary tract obstructions after primary laparoscopic hepaticojejunostomy in children with choledochal cysts. Surg Endosc 2016;30(9):3910-3915. 